\title{
Rheological investigation and simulation of a debris-flow event in the Fella watershed
}

\author{
M. A. Boniello ${ }^{1}$, C. Calligaris ${ }^{1}$, R. Lapasin ${ }^{2}$, and L. Zini ${ }^{1}$ \\ ${ }^{1}$ Geosciences Department, University of Trieste, Trieste, Italy \\ ${ }^{2}$ DiCAMP, University of Trieste, Trieste, Italy
}

Received: 10 November 2009 - Revised: 15 February 2010 - Accepted: 30 March 2010 - Published: 10 May 2010

\begin{abstract}
To set an approach for the future territorial planning, the Geological Survey of Friuli Venezia Giulia Region, through the researchers of Trieste University, started a program of debris-flow risk analysis using Flo-2D software as tool to delimit the hazardous areas. In the present paper, as a case study, a debris flow, called Fella sx, occurring in a torrent catchment was analyzed. The choice was due to the abundance of information about past events, inundated areas, rain fall, geology and to its representativeness. An initial back-analysis investigation identified a couple of representative rheological parameters. Riverbed samples were collected, sieve analyses were performed and rheological tests were carried out on the fraction finer than $0.063 \mathrm{~mm}$ using a rotationally controlled stress rehometer equipped with the serrated parallel plate geometry. The shear dependent behaviour was examined at different concentrations ranging from 33 to $48 \%$, by weight. Viscosity data treatment was performed to determine the most suitable rheological model to provide the best approximation of the debris-flow behaviour. The rheological parameters, derived from experimental data, were used and compared with those obtained through the back-analysis and with the real inundated area. Data obtained through rheological analysis are useful in constructing scenarios of future events where no data for back-analysis are available.
\end{abstract}

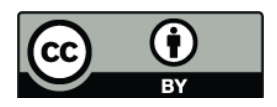

Correspondence to: C. Calligaris (calligar@units.it)

\section{Introduction}

Debris flows are one of the most dangerous and destructive processes that concern mountain areas (Cavalli et al., 2005). The knowledge of the possible inundation areas, the thickness of the deposits and the velocity expressed during the event are really useful to define, but especially to delineate the vulnerable areas in order to identify the structural and non-structural mitigation measures that have to be realized to protect the existing infrastructures.

The debris flow is often considered to be a mixture of viscous slurry, consisting of finer grain sizes and water, and coarse particles (Scotto di Santolo, 2008). The volume and the composition of the mixture are the main factors that contribute to determine the hazards associated with such phenomena, since they govern the mobility and impact energy of the debris (Iverson, 1997; Jakob, 2005). During the last years, several simulation models and approaches have been implemented (Cesco Bolla, 2008; Pirulli, 2005; Peressi, 2003; Rickenmann, 1999) and created to reconstruct a debris-flow phenomena, but a believable scenario can be obtained only by resorting to real parameters that are suitable to characterise the involved material (Sosio et al., 2006). Thus, it is necessary to calibrate those computational codes through back-analysis simulations and laboratory analysis (Tecca et al., 2006).

The studied area is located in the north eastern part of Italy (Municipality of Malborghetto-Valbruna) in Val Canale Valley. The area of interest is a tributary of the Fella River called "Fella sx". During the flood event, which occurred on 29 August 2003, the small river overflowed and a large amount of deposit inundated the A23 Highway covering both lanes.

Published by Copernicus Publications on behalf of the European Geosciences Union. 

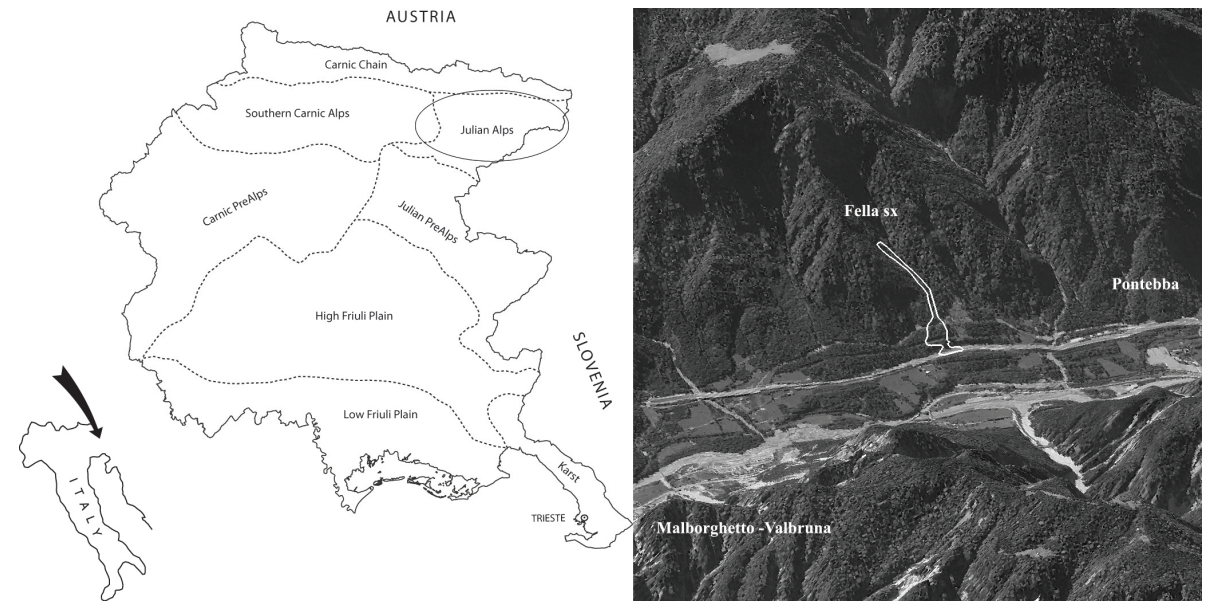

Fig. 1. Location area.

The objective of the present study is to execute a simulation of the debris-flow event which occurred with a numerical code in order to determine if simulation results with rheological parameters obtained through laboratory analyses are comparable with results obtained with parameters calculated through back analyses. The aim has been reached through 2 steps. First of all, rheological parameters available in literature were used to obtain a back analyses simulation. Twelve couples of viscosity and yield stress were used. Among all the simulations obtained, the one that best fitted the event occurred has been chosen. The second step was to collect samples and to realize grain-size and rheological analyses. With the laboratory values obtained (viscosity and yield stress), another simulation has been realized. The results were compared not only among each other, but also with the real event in order to understand the applicability range of data achieved by laboratory analyses through the instrument used.

All these simulations have been realized through the commercial software FLO-2D (2007 version).

The location of the investigated area is shown in Fig. 1.

\section{The main flood event, geological framework, morphometric characterisation}

The area of the Val Canale, Canal del Ferro and Val Aupa, with the whole north eastern part of the Friuli Venezia Giulia Region as well, was invested by a high intensity rainfall on 29 August 2003. The rainfall started at midnight, firstly affecting the areas belonging to the upper sector of the mountains around Cucco, Malborghetto and Ugovizza, then it gradually moved downwards with increasing intensity. A total value of $293 \mathrm{~mm}$ rainfall was recorded by the Pontebba pluviometric station from $02 \mathrm{~h} 00$ to $18 \mathrm{~h} 00$.

Around 18h30, some impressive waves plunged with unexpected violence, power and noise, an avalanche of water, big rocks and trunks crashed against courtyards, houses and went inside windows. This event caused the death of two people, 300 lost their homes, 260 buildings were damaged and substantial damage to infrastructures that remained out of action for several days. The mobilization of more than a thousand landslides occurred along both sides of Val Canale Valley (Russo, 2003).

Hydrological analyses were performed using data recorded by Pontebba's rain-gage. This instrument is part of the network managed by the Regional Directorate of Civil Defence. Data is available at an interval time of $30 \mathrm{~min}$. Maximum values of $50.8 \mathrm{~mm}$ in $30 \mathrm{~min}$ (between $17 \mathrm{~h} 00$ and 17h30), $88.6 \mathrm{~mm}$ per hour (from $15 \mathrm{~h} 30$ to $16 \mathrm{~h} 30$ ), $233.4 \mathrm{~mm}$ in three hours (between $14 \mathrm{~h} 30$ and $17 \mathrm{~h} 30$ ) and $343.0 \mathrm{~mm}$ in six hours (from midnight to $18 \mathrm{~h} 00$ ) were observed. The total influx of the meteorological event, which lasted about $12 \mathrm{~h}$, was equal to $389.6 \mathrm{~mm}$. Regarding the return time characterising the event, there is a considerable variation dependent on the period: between 1 and $24 \mathrm{~h}$, the time of delivery is between 50 and 100 years; for $12 \mathrm{~h}$ it is between 200 and 500 years, while, for a period from 3 to $6 \mathrm{~h}$, return period varies between 500 and 1000 years (Borga et al., 2007).

From a geological point of view, the substrate lithostratigraphic units that outcrop in the studied area are essentially represented by formations chronologically included between post-hercynian Palaeozoic sequence and Mesozoic sequence comprehending the following geological formations (Carulli, 2006): Serla Dolostone (middle Triassic), Werfen Formation (Triassic inf.) and Bellerophon Formation (Permian sup.). The debris present in the riverbed is a coarse deposit of clasts belonging to the formations present in the area. They are predominantly terrigenous belonging to Campil Member, constituted by fine grained sandstones, red and multicoloured marly shales. Furthermore, also the Mazzin Mb. and the Andraz Oz. are represented. Oolitic limestones, grey, 


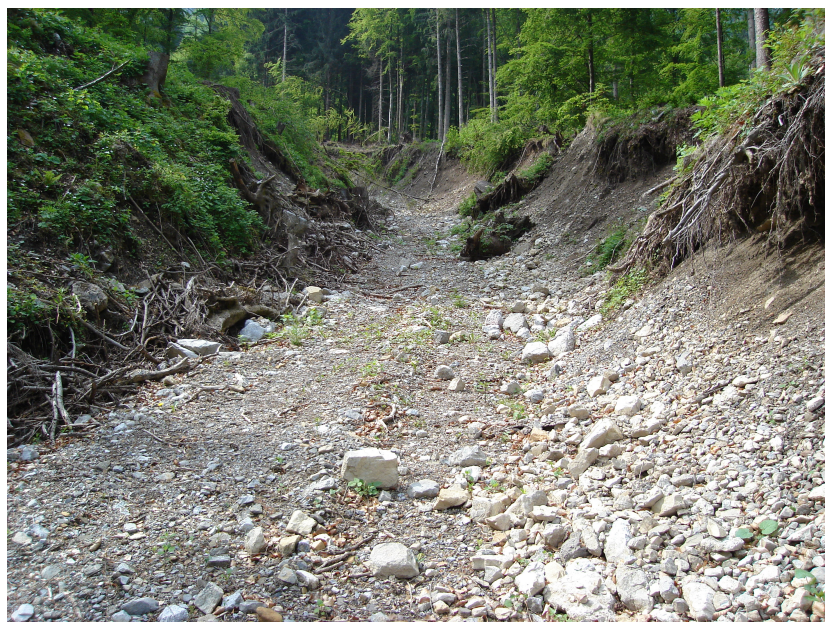

Fig. 2. Fella sx channel after the alluvial event of August 2003. At the centre of the image, the maximum size of rocky fragments present in the channel, $0.04 \mathrm{~m}$.

sometimes marly limestones, are detectable. Bellerophon Formation is present with dark grey limestones clasts having frequent bioclasts. Quaternary is present by fluvial gravelysand deposits and by moraine and till deposits highlighted by the erosions on the riverbed banks.

From a structural point of view, the tectonic features affecting the portion of territory studied are linked to the alpine orogeny and they are marked by wide monoclinal structures separated by tectonic relocations extended with east-west prevailing trends. From the geomechanical point of view, stress associated with bending and faults generated intense fracturing in the rocks making them weaker.

The geological and geomorphological settings of the investigated area are characterised by rocky slopes outcropping with continuity in the site. Frequently, slopes are interrupted by channels located along the secondary structural lineaments orientated NE-SW orthogonally with respect to the principal valley. The channels and the toe of the slopes are partially covered by coarse debris deposit. Their genesis is due to rock fall from the top of the slopes originating from the climatic erosion of the outcropping rocks, or due to till deposits from Quaternary. The essentially limestone and sandstone nature of the clasts, present in the riverbed, reflect the general lithology of the rocky slopes. The deposits consist of coarse gravels mixed with fluvial gravely sand deposits immersed in a finer matrix made of silt and clay (Fig. 2). The morphology of the occurred event was outlined during the geomorphological investigation made by the researchers just after the alluvial event. The mapping, with the extent of the debris-flow deposit obtained through the survey, was used as reference for the different scenarios realized through the simulations.

The main morphometric characteristics of the Fella sx drainage basin are summarized in Table 1.
Table 1. Principal morphometric parameters of the Fella sx drainage basin.

\begin{tabular}{ll}
\hline \multicolumn{2}{c}{ FELLA SX } \\
\hline \multicolumn{1}{c}{ Drainage basin } \\
\hline Outflow point E (m) & 2397050 \\
Outflow point N (m) & 5150290 \\
Watershed area $\left(\mathrm{km}^{2}\right)$ & 0.0595 \\
Watershed perimeter $(\mathrm{m})$ & 1690 \\
Minimum elevation (m.s.l.m.) & 823.86 \\
Maximum elevation (m.s.l.m.) & 1155 \\
Medium elevation $(\mathrm{m} . \mathrm{s} .1 . \mathrm{m})$. & 988.08 \\
Minimum slope $\left(^{\circ}\right)(\mathrm{m} / \mathrm{m})$ & $33.74^{\circ}(0.66)$ \\
Maximum slope $\left(^{\circ}\right)(\mathrm{m} / \mathrm{m})$ & $59.61^{\circ}(1.70)$ \\
\hline \multicolumn{1}{c}{ Stream } \\
\hline Stream length $(\mathrm{m})$ & 650.26 \\
Stream slope $\left({ }^{\circ}\right)(\mathrm{m} / \mathrm{m})$ & $26.88^{\circ}(0.507)$ \\
\hline
\end{tabular}

The watershed is a small area of $0.0595 \mathrm{~km}^{2}$ where the maximum elevation is $1155 \mathrm{~m} \mathrm{~s}$.l.m. with a very high slope angle of 59.6 degrees. The drainage network is not completely well developed. A unique channel is present with a length of about $650 \mathrm{~m}$ and a mean slope of about 27 degrees. Figure 2 shows the material filling the channel. The maximum fragment size is $0.04 \mathrm{~m}$. From the lateral banks visible along the flanks of the channel, it is possible to appreciate the thickness of the till deposit present in the area (about $2.5 \mathrm{~m}$ ). The material involved in the occurred debris flow is produced by erosional phenomena and shallow landslides affecting the outcropping calcareous rocks in the upper part of the basin, while, along the channel, the flow takes charge of the moraine loose material covering the toe of the slopes. Inside the channel, a consistent amount of still mobilizable material is present. During the event, the channel was eroded creating the flanks visible in Fig. 2. During the alluvial event of 2003, the debris flow involved an estimated total volume of about $6000.00 \mathrm{~m}^{3}$.

\section{Experimental data analysis}

\subsection{Grain-size analysis}

In order to determine the rheological parameter values characterising the behaviour of a debris flow, it was realized, at first, a grain-size analysis was needed and later rheological ones. Seeing that debris flows are characterised by poorly sorted deposits (Iverson, 1997), the choice of the sampling point is important in order to collect meaningful samples. The size of each sample corresponded to $25-30 \mathrm{~kg}$ (Lancellotta et al., 1994). The rougher part of the debris was omitted during the sampling phase (big boulders were not collected). 


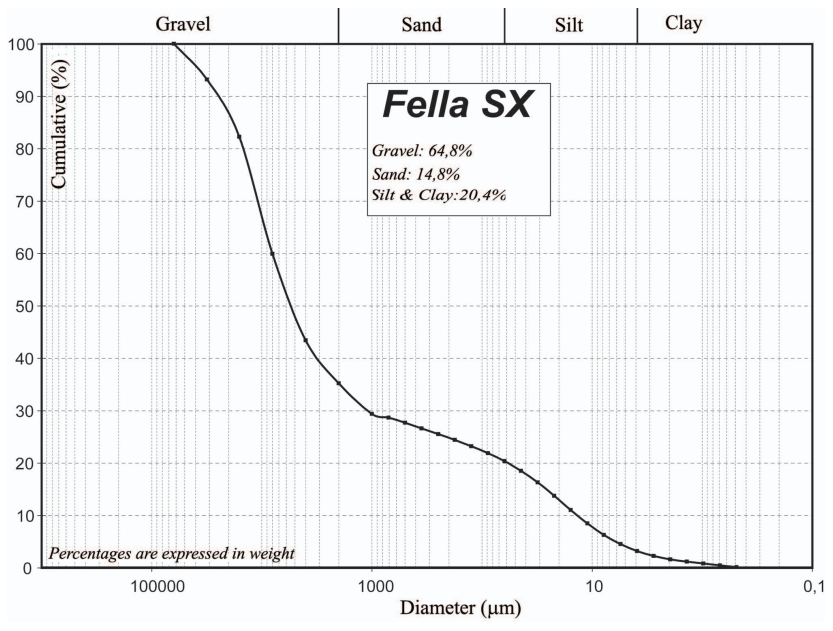

Fig. 3. Grain-size cumulative distribution for the sample collected at the Fella sx watershead.

As shown in Fig. 2, the maximum diameter detected along the riverbed was about $0.04 \mathrm{~m}$. Along the flanks, inside the moraine, are probably boulders of bigger dimensions present, but they are not visible at first sight. After the sampling phase, each sample was prepared for the grain-size analysis. First of all, large samples must be divided using a sample splitter, in this way each new sample is representative of the entire sample. Each subsample weighed about $3 \mathrm{~kg}$. This quantity was calibrated on the vertical sieve characteristics. After the weighing of the sample in dry conditions, a first wet sieving was realized with a $2 \mathrm{~mm}$ sieve, in order to separate the silt and sand from the gravel. The gravel screening was carried out on a dry sample using a vertical sieve separator (Retsch AS300). The following sieves were used: $128 \mathrm{~mm}$, $63 \mathrm{~mm}, 31.5 \mathrm{~mm}, 16 \mathrm{~mm}, 8 \mathrm{~mm}, 4 \mathrm{~mm}$ and $2 \mathrm{~mm}$.

For diameters inferior than $2 \mathrm{~mm}$, it was possible to proceed with wet sieving by sieves in the range of 1.0 $0.063 \mathrm{~mm}$. A representative sample of the fraction passing the $1 \mathrm{~mm}$ sieve was used for the laser diffraction analysis with the Mastersizer 2000S instrument. The grain-size curves obtained through the sieves (weight) and the laser diffraction (volume) were joined together by converting the sand and silt (diameter less than $1 \mathrm{~mm}$ ) volume percentages into weight percentages.

In the investigated area, fan deposits consist of sharpangled fragments, immersed in a gravel matrix (the predominant class ranging from about $95 \%$ to $35 \%$ ) and subordinate sand (from $35 \%$ to $20 \%$ ) than silt and clay, matrix in the silt seems to have a significant percentage, probably as a result of the lithology degradation. The sample collected along the river bed, is constituted by polygenical fragments of dolomitic limestones and terrigenous rocks. During the survey, boulders of variable size (from $\mathrm{cm}^{3}$ to $\mathrm{dm}^{3}$ ) were found immersed in the matrix.
Figure 3 reports the results obtained by the grain-size quick analysis: $64.8 \%$ of gravel, $14.8 \%$ of sand and $20.4 \%$ of silt and clay, this means that the sample is a gravel with sandy silt (Cucchi et al., 2008). The shape of the grain-size distribution curve highlights a poorly sorted mixture typical of this kind of deposit.

\subsection{Rheological analysis}

The rheological study concerned only the fine fraction passing the $0.063 \mathrm{~mm}$ sieve. Suspensions with different water contents $(33,36,40,44$ and $48 \mathrm{wt} \%)$ were prepared from this fraction.

The experimental tests were performed using a controller stress rheometer (Rheostress Haake RS150, Haake GmbH, Germany) equipped with a parallel plate geometry $(35 \mathrm{~mm}$ diameter, 1-mm gap), with rough surfaces to eliminate the wall-slip phenomena. The gap is compatible with the top size of the solid fraction used for sample preparation. An oil film was deposited on the interface sample/air in order to overcome or reduce the problem related to the evaporation of water from the free surface of the sample.

Tests under controlled stress conditions were performed in the low shear region, where a transition from continuous deformation to developed flow can be detected. Controlled rate tests served to determine viscosity values at higher shear rate conditions.

In the previous tests, the procedure consisted of a stepwise sequence of increasing stress values applied to the sample and the corresponding shear rates were measured. The stress was kept constant within each step until the relative shear rate variation satisfied the following constraint, $\left(\Delta \gamma^{\prime} / \gamma^{\prime}\right) / \Delta t \leq$ $0.05 \%$, or the measurement was longer than the cut off value of $90 \mathrm{~s}$. The latter procedure consisted of a logarithmic sequence of increasing shear rate (from 1 to $1000 \mathrm{~s}^{-1}$ ). Data obtained from the stepwise stress sequence is used to characterise the steady behaviour in the lower stress range and to estimate the yield stress, if present. Figure 3 clearly illustrated that all the examined systems exhibited an apparent plastic behaviour. A Newtonian plateau can be noted at low stresses, whose viscosity value markedly increases with decreasing water content. After that, a dramatic drop in viscosity is observed, which covers more than four decades in a very narrow stress range. This means that an apparent yield stress $\sigma_{y}$ can be arbitrarily located within this range, corresponding to the minimum force necessary to produce an appreciable flow of the system. Indeed, a continuous deformation is recorded even at stresses lower than $\sigma_{y}$, and its value progressively increases with increasing $\sigma$. It is worthwhile to note that, for all the systems, the transition from small but continuous deformation to appreciable flow conditions takes place in quite a narrow strain range (from 0.3 to 0.6 ) in front of the wide interval obtained for the yield stress values (from 4 to 2500 Pa) (Fig. 4). 

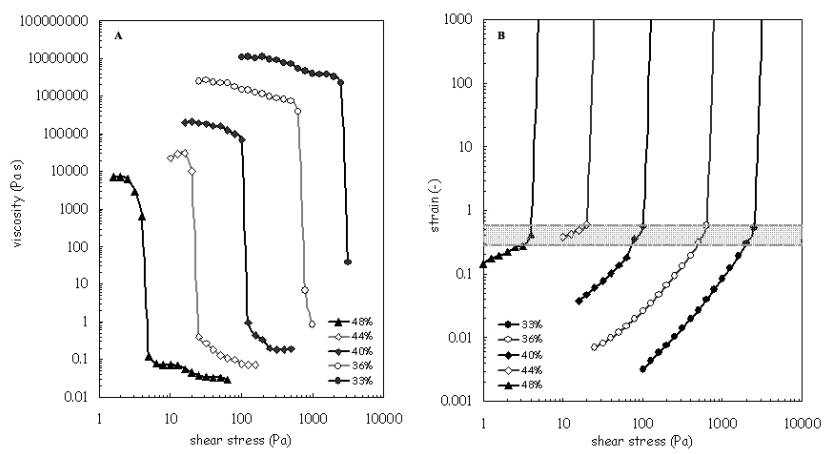

Fig. 4. (A) Plastic behaviour shown by the investigated samples; (B) strain range (gray stripe) representing data from small but continuous deformation to appreciable flow conditions.

The controlled stress stepwise procedure is suitable to characterise the viscous behaviour of such plastic systems at medium-high shear conditions, provided that only the increasing stress sequence is composed of very short incremental steps. More convenient is the shear rate sequence, which allows the system to be guided from low to high shear in a controlled way. Figure 4 reports the flow curves obtained for all the systems.

Data can be correlated with acceptable approximation by the Bingham model (the calculated curves are plotted in Fig. 5). No significant improvement of the fitting quality can be obtained by resorting it to three-parameter models (the Herschel-Bulkley equation, or the generalized Casson model).

Table 2 reports the parameters of the Bingham model (the Bingham yield stress $\sigma_{B}$ and the plastic viscosity $\eta_{p}$ ) and the experimental yield stress $\sigma_{y}$. It is clearly evident by the strong correlation between the two yield stresses, being $\sigma_{y} \cong$ $2 \sigma_{B}$.

The Bingham yield stress $\sigma_{B}$ and the plastic viscosity $\eta_{p}$ are usually correlated with the solids volume concentration $C_{v}$ with empirical expressions:

$\eta_{p}=\alpha e^{\beta C_{v}}$

$\sigma_{B}=\gamma e^{\delta C_{v}}$

The fitting coefficients $\alpha, \beta, \gamma, \delta$ are reported in Table 3, together with the coefficients of determination $r^{2}$.

The choice of such exponential relationships is dictated by reasons of convenience, since the results can be easily compared with other data from literature through the fitting coefficients, but they do not satisfy two physical constraints which appear evident at low and high solids content. Indeed, the viscosity must diverge as $C_{v}$ approaches the maximum packing volume fraction $C_{v \text {, max }}$, when no flow condition can take place owing to interparticle contact and friction. This explains why a better correlation between the plastic viscosity and the solids volume content can be provided by an
Table 2. Data obtained from the Bingham model and the experimental yield stress.

\begin{tabular}{llrrrrr}
\hline$\%$ & & 33 & 36 & 40 & 44 & 48 \\
\hline$C_{v}$ & & 0.421 & 0.389 & 0.349 & 0.313 & 0.279 \\
$\sigma_{B}$ & $(\mathrm{~Pa})$ & 1254 & 261 & 132 & 25.0 & 2.03 \\
$\eta_{p}$ & $(\mathrm{~Pa} . \mathrm{s})$ & 30.5 & 1.40 & 0.12 & 0.10 & 0.06 \\
$\sigma_{y}$ & $(\mathrm{~Pa})$ & 2500 & 630 & 100 & 20.0 & 4.0 \\
\hline
\end{tabular}

Table 3. The fitting coefficients $\alpha, \beta, \gamma, \delta$; with the coefficients of determination $r^{2}$.

\begin{tabular}{cccc}
\hline & $\alpha$ & $\beta$ & $r^{2}$ \\
\hline$\eta_{p}$ & $2 \mathrm{E}-07$ & 42.23 & 0.846 \\
& $\gamma$ & $\delta$ & \\
$\sigma_{B}$ & $5 \mathrm{E}-05$ & 42.01 & 0.952 \\
\hline
\end{tabular}

asymptotic expression, resembling those normally used in suspension rheology for the relative viscosity, such as the Quemada equation. Furthermore, the plastic behaviour appears above a critical concentration of the disperse phase $C_{v, 0}$, and then also the dynamic yield stress derived from data fitting begins to have a physical meaning above such minimum solids concentration.

\section{Numerical simulation model}

FLO-2D is a 2-dimensional flood-routing model of volume conservation that routes a flood hydrograph while predicting floodwave attenuation due to flood storage. Hyperconcentrated sediment flow can be simulated by this software based on a model using a quadratic rheological model that includes viscous stress, yield stress, turbulence and dispersive stress terms as a function of sediment concentration. The model uses the full dynamic wave momentum equation and a central finite difference routing scheme with eight potential flow directions to predict the progression of a flood hydrograph over a system of square grid elements. Wave propagation is fully controlled by topography and roughness or resistance to flow. The model is suitable to analyse problems of flood flows such as unconventional, not confined on an alluvial fan with complex topography, mud flows and debris flows and floods affecting urban areas. FLO-2D model is an effective tool for the evaluation of hazard floods and planning for mitigation measures (O'Brien and Julien, 1988; Calligaris et al., 2008).

The two-dimensional routing model FLO-2D was used to simulate Fella sx debris flow. On a DEM (Digital Elevation Model) with a grid of $5 \mathrm{~m} \times 5 \mathrm{~m}$ obtained from the CTRN Numerical Map of FVG Region (scale 1:5000), a computational 


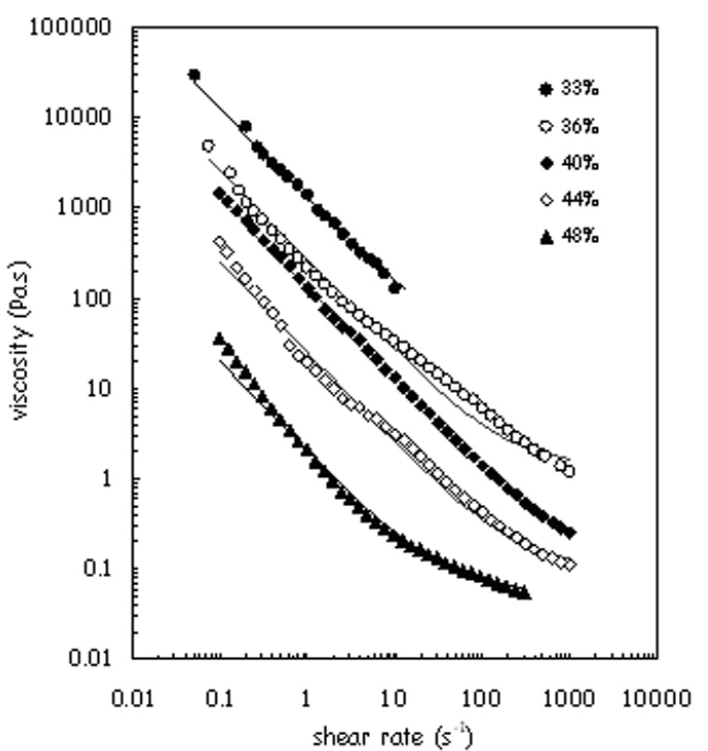

Fig. 5. Experimental data correlated with Bingham model.

domain has been defined. Inflow and outflow points were chosen. The inflow points have been inserted at the top of the fan; outflow points instead are located downstream to the area sampled after the flood event and covered by the alluvial deposits (Fig. 6a).

To predict the hydrograph inserted into Flo-2D, hydrologic model CLEM was used (Borga et al., 2002). The hydrograph has been obtained considering the upper confidence limits of depth-duration-frequency curve for a return period of 200 years (Borga et al., 2002; Tecca et al., 2006). To start the back analyses simulation, the main peak (Fig. 6b) was chosen from the available hydrograph between $17 \mathrm{~h} 10$ and 18h50 (Tecca et al., 2006). Using this time interval, the total mobilized volume obtained from the simulations resulted in $5600.00 \mathrm{~m}^{3}$. The eyewitnesses enhanced the possibility that the event evolved in subsequent waves, for this reason it has been decided to insert a hydrograph covering a longer period starting from $16 \mathrm{~h} 00$ until $18 \mathrm{~h} 50$. Different simulations have been realized, initially only with the main peak, later increasing the value by adding the previous peak. It has been observed that the increased hydrograph is not developing significant variations in the volume values involved and in the inundated area obtained.

For the back analyses, 30 simulations with 12 couples of different rheological parameters have been realized, reconstructing different scenarios of a possible event.

The 12 parameters couples have been chosen from the ones available on literature, trying to favour the ones that have similar geomorphological and lithological characteristics to the one present in the studied area (O'Brien et al., 1988; Tecca et al., 2006; D'Agostino et al., 2006). Among these values - the viscosity and yield stress that reproduced the better phenomena that occurred - were $\eta\left(\alpha=4.95 \times 10^{-5}\right.$ and $\beta=27.1)$ and $\sigma\left(\gamma=3.8 \times 10^{-2}\right.$ and $\left.\delta=19.6\right)$ answering to Aspen Watershed model (O'Brien et al., 1988) related to a Concentration by volume $\left(C_{v}\right)$ of 0.50 .

The Manning's n-value was 0.1, typical for open ground with debris; the specific weight of the mixture $\gamma_{m}$ and the resistance parameter for laminar flow $K$, were assumed equal to $26.5 \mathrm{KN} / \mathrm{m}^{3}$ and 2085 , respectively, suggested values for debris flow (Tecca et al., 2006; O'Brien, 1988).

Once the experimental data has been obtained, a new event was simulated with the resulting parameters. Only the viscosity $\left(\alpha=2 \times 10^{-7}\right.$ and $\left.\beta=42.23\right)$, yield stress $\left(\gamma=5 \times 10^{-5}\right.$ and $\delta=42.01)$ and relative $C_{v}$ value $(0.421)$ have been changed. The result obtained is represented in Fig. 7. The figure replicates the extension of the inundated areas and the thickness of the debris deposits in three different situation: 7a is an image of the occurred debris flow outlined few days after the alluvial event; $7 \mathrm{~b}$ represents the best scenario obtained through the back-analysis; $7 \mathrm{c}$ is the simulation obtained using rheological parameters coming out from the experimental data. The maximum thickness of the deposit (between $2.01 \mathrm{~m}$ and $2.40 \mathrm{~m}$ ) reached in the simulations has been $2.10 \mathrm{~m}$ in the middle part of the channel (Fig. 7b) and $2.40 \mathrm{~m}$ corresponding to the highway guard rail that created a barrier to the flow (Fig. 7c).

\section{Results and discussion}

Debris flows are complex phenomena, due to spatial and temporal variability in material properties (Sosio et al., 2007; Scotto Di Santolo and Evangelista, 2008), they are made up of soil, rock and water (Pirulli et al., 2008). Their flow characteristics depend on the water content, sediment size and/or sorting, and on the dynamic interaction between the solid and fluid phases (Pirulli et al., 2008). In particular, the rheological properties naturally change, even during a single debris-flow event (Remaitre et al., 2005) or still for debris flows taking place in the same torrent (Arattano et al., 2006). Even if there are so many variabilities and uncertainties in the choice of the rheological parameters, they are generally required by numerical models to replicate debris-flow events, and the models outcome are very sensitive to the wide variability of them (Arattano et al., 2006). This implies that, for purposes of hazard prediction and assessment on a debris fan, different simulations have to be performed assuming different rheological behaviours and exploring the related consequences (Arattano et al., 2006).

In the present paper, experimental data obtained from the rheological analysis have been compared with the ones obtained through back-analysis performed by applying the Flo$2 \mathrm{D}$ code (Fig. $7 \mathrm{~b}$ and c). The comparison between data permitted to better characterise the rheological behaviour of the Fella sx debris flow and to evaluate the adequacy of the data obtained through two different approaches: experimental and empirical and the code used. 

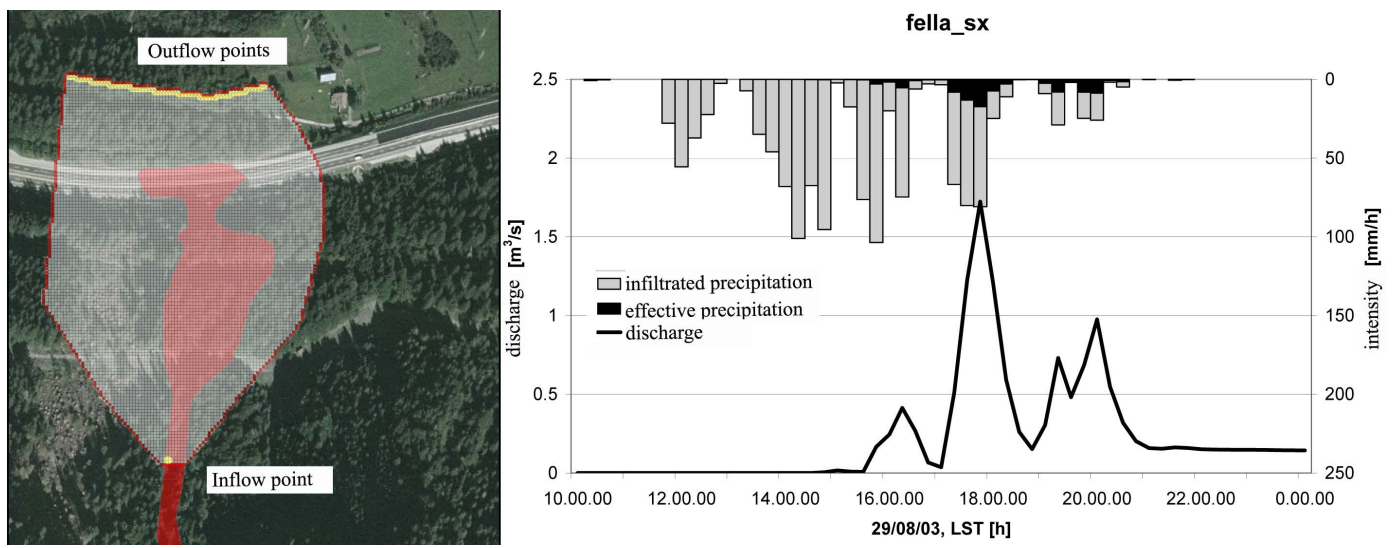

Fig. 6. (A) In light grey: computational domain area. Inflow point at the top of the fan (yellow point), outflow points downstream (yellow line). (B) Complete hydrograph: only a part of it has been used as input parameter for the simulation, 16h00-18h50
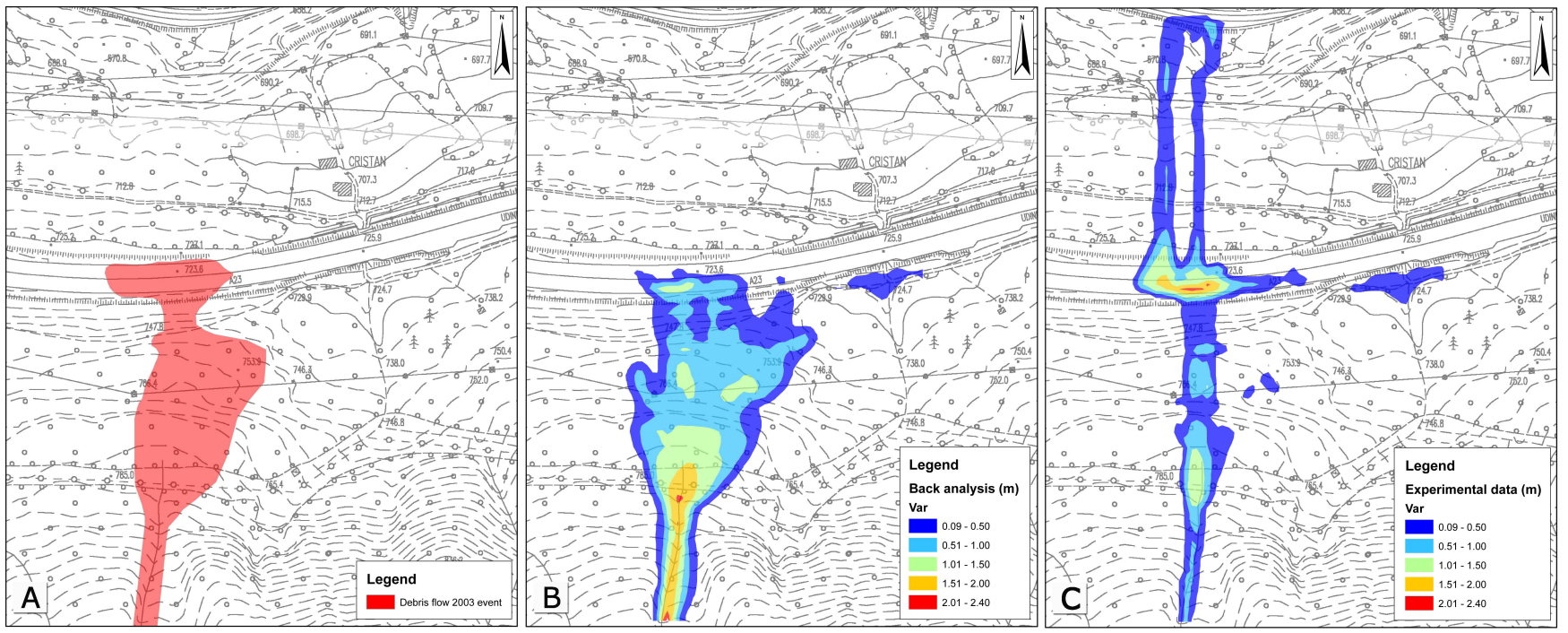

Fig. 7. (A) Inundated area bounded just after the 2003 alluvial event; (B) back-analysis simulation: inundated area and debris thickness with rheological parameters from Aspen Watershed model; (C) scenario of debris-flow event simulated with rheological parameters obtained through experimental data.

The shape of the inundated area obtained through backanalysis simulation is comparable (Fig. 7a vs. 7b) to the one bound just after the event: the extent of the back-analysis inundation area exceeds the observed one by $24.70 \%$, whereas the mean deposit thickness is $15-20 \%$ more, with a slight fall of total volumes deposited on the fan. The maximum flow thickness attained along the channel and in the depositional area is in good agreement with field values (Fig. 7B), the flow during the simulation initially remains inside the channel and then spreads over the plain just after the fan apex.

In the simulation obtained with the experimental data, the extent of the inundation area exceeds the observed one by $29.00 \%$, whereas the maximum deposit thickness is $17 \%$ more. The total run distance is different from the one simulated through the back-analysis. During the event there was no evidence of debris downstream on the highway, only the water crossed the highway. The maximum flow thickness obtained along the channel and in the depositional area is consistent with field values and with previous simulations (Fig. 7c).

In both cases, the scenarios over estimated the real flooded areas, this means that the results are on the safe side.

The discrepancy between the simulated areas and the boundary obtained in the survey could be due to several reasons:

1. The choice of the most reliable pair of rheological parameters for the debris-low event is crucial, the one chosen from literature, could not be representative of the lithological and geomorphological characteristics of 
the studied area. Since the dynamic behaviour of a debris flow changes in time and also changes for different events any choice regarding the rheological parameters for debris-flow hazard purposes is inevitably affected by uncertainties (Arattano et al., 2006).

2. The use of Flo-2D code, for small watershed, like the one studied during this research, is an instrument that may overestimate the flooded area.

3. Flo-2D code is not able to recreate the erosion in the flooded channel. It is possible to know the hydrograph and the relative $C_{v}$ values in the input point, but it is impossible to modify the $C_{v}$ along the course of the flooding area, so it is difficult to recreate the correct concentration by volume of the total involved material in all the points of the computational domain.

4. The cell size used to recreate the surface on which the hydrograph is flooding, is really important for the morphometrical shape of the depositional fan and the courses of flooding; the smaller the cell size, the more precise the course of the flow. To have a detailed DEM, it is necessary to start from laser scanner data; in this case, there were none available, only data coming from CTRN cartography.

5. The importance of the instrument used for the rheological analysis: it should be important to compare results obtained with the Rheostress Haake RS150 $(<0.063 \mathrm{~mm})$ and with a rehometer that takes into account bigger grain sizes (e.g. BMS-ball measuring system for samples up to $5 \mathrm{~mm}$ ).

6. The effect, not negligible, like Sosio et al. (2006) says, of the frictional component owing to the coarse fraction that is not possible to include in the laboratory analysis. This means that there is an underestimation of the yield strength coefficients derived by direct measurements due to the maximum grain size used in the rheological analyses (Coussot et al., 1998; Iverson, 2003). In the present case, the material with the grain size diameter up to $0.063 \mathrm{~mm}$ is representing $20.4 \%$ of the whole sieved material. This results in a sample that is not representative of the total grain-size distribution (Ancey, 2007; Iverson, 2003). For the whole grain size distribution, the yield strength value results both from colloidal interactions, provided by the finer fractions, and from the frictional contacts, experienced by the coarse-grained material (Rodine et al., 1976; Coussot et al., 1998; Iverson, 1997, 2003). In the Fella sx event, with the amount of the coarse debris involved (up to $20 \%$ coarser than $0.2 \mathrm{~m}$ ), it is reasonable to suppose that the grain to grain interactions are not negligible.
Table 4. Comparison between coefficients obtained through laboratory analysis $\left(\eta_{p}, \sigma_{B}\right)$ and back-analysis $(\eta, \sigma)$.

\begin{tabular}{ccccl}
\hline & $\alpha$ & $\beta$ & $C_{v}$ & \\
\hline$\eta_{p}$ & $2 \mathrm{E}-07$ & 42.23 & 0.421 & Experimental \\
& $\gamma$ & $\delta$ & 0.421 & \\
$\sigma_{B}$ & $5 \mathrm{E}-05$ & 42.01 & 0.421 & Experimental \\
& $\alpha$ & $\beta$ & 0.500 & \\
$\eta$ & 0.000495 & 27.1 & 0.500 & From back analyses \\
& $\gamma$ & $\delta$ & 0.500 & \\
$\sigma$ & 0.0383 & 19.6 & 0.500 & From back analyses \\
\hline
\end{tabular}

7. For studying debris-flow rheological parameters, it is possible to apply different rheological models. In the present case, the Bingham model and the quadratic rheological are the ones that are better fitted for the experimental data. But also the Vollemy and the HerschelBulkley can be used to obtain viscosity and yield stress. Not all the simulation software base their calculations on the same models. In this case Flo-2D, our chosen code, is based on Bingham and Quadratic rheological models (O'Brien, 1988).

The laboratory analyses and the field observations provide a tool to characterise the rheological properties of the flowing debris, and to constrain the routing model parameters needed to replicate the debris-flow event (Sosio et al., 2007). The approaches used to derive at the rheological parameters have limitations and a certain degree of uncertainty. These approaches provide different estimates for the required parameters, in range and magnitude (Table 4). Usually the empirical estimations based on field evidence are more representative of the overall behaviour of the debris flow, but on the basin studied, the estimated rheological parameters improves on the behaviour of the event even if the empirically estimated yield strength and viscosity exceed the directly measured ones by an order of magnitude 3 for $\alpha$ and $\gamma$, and are double for $\beta$ and $\delta$ (Table 4).

This demonstrates the difficulty in recreating the correct parameters to simulate a debris-flow event. Modelling debris-flow processes requires many simplifications, causing model simulations to diverge more or less from reality. For debris-flow events composed of a large number of coarse clasts, the rheometrical-test results can be used carefully in the Flo-2D model for predictive purposes. Where possible, a back-analysis for the yield strength and viscosity parameters is reasonable. In the present case, the models obtained with both rheological parameters are able to represent the event, and the one in which the experimental data has been used, better characterise it. So, in conclusion, it is possible to say that Flo-2D is a useful instrument to investigate the territory and to realize simulations of debris-flow phenomena, uncertainties can be reduced using more than one code 
and rheology. Of course, it is not an exhaustive methodology, it guarantees the possibility of recreating different scenarios and, working in a 2-D space, to chart the possible inundate areas and especially this last characteristic is useful for local authorities to carry out future territorial planning in order to define the hazardous portions of the territory.

Acknowledgements. This work has been funded in part by the Geological Survey of Friuli Venezia Giulia Region; the authors wish to thank Borga M. and Sangati M. (University of Padova - AGRIPOLIS), who supplied the hydrographs, also Cucchi F. (University of Trieste - DiSGAM) for the suggestions provided and for critically reviewing the paper.

Edited by: L. Franzi

Reviewed by: two anonymous referees

\section{References}

Ancey, C.: Plasticity and geophysical flows: A review, J. NonNewton-Fluid, 142, 4-35, 2007.

Arattano, M., Franzi, L., and Marchi, L.: Influence of rheology on debris-flow simulation, Nat. Hazards Earth Syst. Sci., 6, 519528,2006 , http://www.nat-hazards-earth-syst-sci.net/6/519/2006/.

Borga, M., Boscolo, P., Zanon, F., and Sangati, M.: Hydrometeorological analysis of the August 29, 2003 flash flood in the eastern Italian Alps., J. Hydrometeorology, 8(5), 1049-1067, 2007.

Borga, M., Dalla Fontana, G., and Cazorzi, F.: Analysis of topographic and climatic control on rainfall-triggered shallow landsliding using a quasi-dynamic wetness index, J. Hydrol., 268(14), 56-71, 2002.

Calligaris, C., Boniello, A. M., Zini, L.: Debris flow modelling in Julian Alps using FLO-2D, in: Monitoring, Simulation, Prevention and Remediation of Dense and Debris Flows, edited by: Lorenzini, G., Brebbia, C. A., and Emmanouloudis, D. E., Southampton, WIT Press, 60, 81-88, 2008.

Cavalli, M. and Grisotto, S.: GIS-based identification of debrisflow dominated channels: application to the upper Avisio Basin (Trento), Servizio Sistemazione Montana della Provincia Autonoma di Trento Interreg III Project Alpine Space, Work Package 7, Innovative Tools for Information Collection, 2005.

Carulli, G. B.: Carta geologica del Friuli Venezia Giulia, edited by: Firenze, S. E. L. C. A., Italy, Map 2006.

Cesco Bolla, B.: Modellazione di colate detritiche: software a confronto, M.S. thesis, Geosciences Department, University of Trieste, Trieste, Italy, 91 pp., 2008.

Cucchi, F., Calligaris, C., Zini, L., et al.: Relazione tecnica illustrativa delle attività scientifiche finalizzate alla realizzazione di uno studio geologico tecnico relativo ai fenomeni di colata detritica in Val Canale, Regione Autonoma Friuli Venezia Giulia, Direzione Centrale ambiente e Lavori Pubblici, Open File Rep.8913, 156 pp., 2008.

Coussot, P., Laigle, D., Arattano, M., Deganutti, A., and Marchi, L.: Direct determination of rheological characteristics of debrisflow, J. Hydraul. Eng., 124, 865-868, 1998.
D'Agostino, V. and Tecca P. R.: Some considerations on the application of FLO-2D model for debris flow hazard assessment, in: Monitoring, Simulation, Prevention and Remediation of Dense and Debris Flows, edited by: Lorenzini, G., Brebbia, C. A., and Emmanouloudis, D. E., Southampton, WIT Press, 90, 159-170, 2006.

Iverson, R. M.: The physics of debris flows, Rev. Geophys., 35, 245-296, 1997.

Iverson, R. M.: The debris-flow rheology myth, in: Debrisflow hazards mitigation: Mechanics, prediction and assessment, edited by: Rickenmann, D. and Chen, C. L., Millpress, Rotterdam, Netherlands, 303-314, 2003.

Jakob, M.: A size classification for debris flows, Eng. Geol., 79, 151-161, 2005.

Lancellotta, R., Scarpelli, G., and Favaretti, M.: Raccomandazioni sulle prove geotecniche di laboratorio, A.G.I., 1-56, 1994.

Peressi, G.: Il rischio da colate detritiche: metodologia di analisi, Dissertation at the Advanced Professional Training, Il rischio idraulico e idrogeologico: studi e proposte operative, Udine, Italy, 30 April 2003, 57, 2003.

Pirulli, M.: Numerical modelling of landslide runout, a continuum mechanics approach, Dissertation, Politecnico di Torino, Torino, Italy, 2005

Pirulli, M. and Sorbino, G.: Assessing potential debris flow runout: a comparison of two simulation models, Nat. Hazards Earth Syst. Sci., 8, 961-971, 2008, http://www.nat-hazards-earth-syst-sci.net/8/961/2008/.

O'Brien, J. S. and Julien, P. Y.: Laboratory analysis of mudflow proprieties, J. Hydraul. Eng., 114(8), 877-887, 1988.

Remaitre, A., Malet, J., Maquaire, O. Ancey, C., and Locat, J.: Flow behaviour and runout modelling of Complex debris flow in a clay-shale basin, Earth Surf. Processes, 30, 479-488, 2005.

Rickenmann, D.: Empirical Relationships for Debris Flows, Nat. Hazards, 19, 47-77, 1999.

Rodine, J. D. and Johnson, A. M.: The ability of debris heavily freighted with coarse clastic materials to flow on gentle slopes, Sedimentology, 23, 213-224, 1976.

Russo, A.: In ginocchio nella melma: documentazione storica suul'alluvione del 29 agosto 2003 e giorni successivi in Valcanale e Canal del Ferro, Voce della Montagna, 2003.

Scotto Di Santolo, A. and Evangelista, A.: Some considerations on debris flow rheology, EGU General Assembly 2008, Geophysical Research Abstracts, Vol. 10, EGU2008-A-07459, SRef-ID: 1607-7962/gra/EGU2008-A-07459, 2008.

Sosio, R., Crosta, G. B., Frattini, P., and Valbuzzi, E.: Caratterizzazione reologica e modellazione numerica di un debris flow in ambiente alpino, Giornale di Geologia Applicata, 3, 263-268, 2006.

Sosio, R., Crosta, G. B., and Frattini, P.: Field observations, rheological testing and numerical modelling of a debris-flow event, Earth Surf. Processes, 32, 290-306, 2007.

Tecca, P. R., Armento, C., and Genevois, R.: Debris flow hazard and mitigation works in Fiames slope (Dolomites, Italy), Trans. Ecol. Environ., 90, 15-25, 2006. 